\title{
Epidemiological Survey of Asymptomatic Bacteriuria in Diabetes Mellitus Patients in Patna, India
}

\author{
Sanjay Kumar ${ }^{1,2}$, Satyendu Sagar ${ }^{3}$, Anjali Awasthi ${ }^{4}$, Jitendra Kumar ${ }^{5, *}$ \\ ${ }^{1}$ Department of Nanoscience and Nanotechnology, AKU Patna, India \\ ${ }^{2}$ Central Diagnostic, India \\ ${ }^{3}$ Department of Microbiology, Nalanda Medical College Hospital, India \\ ${ }^{4}$ Department of Biological Sciences, BITS-Pilani-333031, India \\ ${ }^{5}$ Department of Biotechnology/ Botany, Patna University, India
}

Copyright (C) 2014 Horizon Research Publishing All rights reserved.

\begin{abstract}
To determine the prevalence and etiology of Asymptomatic bacteriuria (ASB) and antimicrobial resistance of urinary isolates among diabetics mellitus and non-diabetics, a total of 200 patients comprising of 120 diabetes mellitus (DM) and 80 non- diabetes were studied. ASB was detected in $36 \%$ patients of which $40 \%$ are diabetic and $30 \%$ are non-diabetic. Coagulase Negative Staphylococcus (CoNS) were the predominant organism $(36.36 \%)$ isolated from the urine of both diabetic and non-diabetic. We observed occurrence of ASB significantly increases with age in DM patients and is more prevalent in DM females compared to non-DM females. Whereas Klebsiella sp., Candida sp., and E. coli were also significantly more prominent in DM patients. Most isolates of Klebsiella sp. and E. coli showed resistances to multiple antibiotics tested. For the uropathogens found in the samples tested Levofloxacin proved to be the most sensitive antibiotic. The study revealed a high prevalence of ASB among DM than non-DM subjects. This study also demonstrates multiple drug resistance observed in both DM and non-DM subjects, therefore irrational and indiscriminate use of antibiotic should be avoided.
\end{abstract}

Keywords Asymptomatic Bacteriuria, Diabetes Mellitus, Drug Resistance, Antibiotic

\section{Introduction}

Diabetes is one of the common metabolic disorders, influenced by genetic, ethnic and socioeconomic factors. World health organization (WHO) has reported that prevalence of diabetes is increasing in developing counties such as India. Diabetes mellitus (DM) patients have been reported to be more predisposed to urinary tract infections (UTI ) [1]. The mechanism of pathogenesis for this association is not fully elucidated however it is suggested that high glucose concentration in urine may favour the growth of pathogenic micro-organism and stimulate UTI [2]. UTI is characterized by bacteriuria which results in both symptomatic and asymptomatic infection. Asymptomatic UTIs are more prevalent in women.

Asymptomatic bacteriuria (ASB) is a form of UTI characterized by the presence of significant amount $>10^{5}$ $\mathrm{cfu} / \mathrm{ml}$ of bacteria in urine $[3,4]$. Several studies have demonstrated the association of ASB with diabetes, and it is also reported that the prevalence is higher in people with diabetes than non-diabetes [5-7]. ASB is common among human population and may lead to serious complications if not properly managed. ASB has been identified as a risk factor for acquiring symptomatic UTI especially in diabetic women. UTI are more severe in diabetic patients involving life-threatening complications such as emphysematous Pyelonephrits, and Renal papillary necrosis [9].

The most frequently isolated ASB in urine includes Escherichia coli, Klebsiella pneumoniae, CoNS, Streptococcus pyogens, Streptococcus agalactiae, and Enterococcus fecalis [3-5]. E. coli is known most common uropathogens; other micro-organisms are prevailing. Antibiotic resistance of uropathogens is increasing due to emerging of multiple drug resistant strains $[3,5,10]$. Levofloxacin has been reported to be effective against most of the urinary isolates $[4,10]$. Currently, there is lack of systematic study in Patna region that describe profile of ASB among DM Patients and non-DM patients. This paper describes the current trends of ASB between DM patients and non-DM patients and their antibiotic resistance properties.

\section{Material and Methods}

A total of 200 patients (120 diabetics and 80 non diabetics) were included in the study, consent was obtained from the patients before sampling. All these patients belong to Patna district, Bihar, India. Urine samples were collected into 
sterile container after proper washing of genitalia to avoid contamination. Samples were placed in refrigerator $\left(4^{\circ} \mathrm{C}\right)$ and further analysed within 8 hours. In case if immediate delivery of the urine sample to the laboratory was not possible, Boric acid $(1 \% \mathrm{w} / \mathrm{v})$ was used as a preservative.

Urine was examined to detect blood, pus, epithelial cell, cast, protein, sugar and any other cells. A calibrated $10 \mu 1$ loop was used to inoculate un-centrifuged urine into Nutrient Agar, MacConkey's Agar, Blood Agar, and Sabouraud's Dextrose Agar and incubated at $37^{\circ} \mathrm{C}$ overnight (about 12-16 hrs). Isolates were identified using standard biochemical techniques. Drug sensitivity test (DST) was carried out by Kirby - Bauer Disc diffusion methods using standard procedures [16].

Antibiotic used in the study were Nalidixic acid, Penicillin, Augmentin Ceftriaxone, Cefuroxime, Ciprofloxacin, Levofloxacin, Gentamicin, Co-trimoxazole, Azithromycin, and Doxycycline. Antibiotics were obtained from Hi Media Laboratories, Mumbai, India.

The statistical analysis of the results was carried out using Chi-square test. P-values $<0.05$ were considered statistically significant.

\section{Result}

\section{Asymptomatic Bacteriuria (ASB) is more prominent in DM female}

To examine the prevalence of ASB in Patna district, 200 patients of different age group of Patna region were tested for ASB in their urine. The distribution of ASB in diabetic and non-diabetic patients according to gender and age is shown in Table 1. There was significant increase in prevalence of ASB with age $(\mathrm{p}<0.05)$ (Table 1). The prevalence of ASB was significantly higher in DM patients in comparison to non DM patients (Table 1). To investigate the relationship between gender, diabetes and ASB; we compared percentage of ASB in male verus female participants and diabetic versus non diabetic. We found that male participants have less percentage of ASB as compared to female participants $(p<0.001)$. There is no significant difference of ASB between male participants of DM and non DM patients $(p=0.31)$. There is significant increase of ASB in female subjects regardless of DM and non DM (Table 1). We observed that DM (female/male) subjects show more prevalence of ASB compared to non DM female/ male $(p=0.005)$. However, altogether these results suggest that diabetic females had highest prevalence of ASB based on the population studied.

P- Values on the table are between diabetic and non-diabetics. NS, S stands for not significant and significant respectively. $\mathrm{N}$ stands for total number of patients. The presence of Asymptomatic Bacteriuria (ASB) in diabetes mellitus female is significantly more in comparison of diabetes mellitus male.

\section{Coagulase negative staphylococci (CoNS) is the most prevalent organism in the urine}

To investigate the occurrence of different bacterial species found in urine of DM and non-DM patients. We tested the presence of bacterial species in urine and analyzed the percentage occurrence. We found the coagulase negative staphylococci were the most prevalent organisms in urine of DM and non-DM patients. The Klebsiella sp. and Proteus sp. were significantly more in non-DM compared to DM $(\mathrm{p}<0.001)$. Candida $s p$, Serratia and Streptococcus $s p$ were found frequently in DM patients. The other species such as $E$. coli and Staphylococcus aureus were found in both DM and non-DM patients. The Proteus $s p$ and Enterobactor were rarely found in urine of DM and non-DM patients (Table 2). All together, it shows that there is wide spectrum of different bacterial species in both diabetics and non-diabetics. However, CoNS is the most prevalent organism in urine of both DM and non-DM patients.

$P$ values on the table are between diabetic and non-diabetics. NS, S stands for not significant and significant respectively. $\mathrm{N}$ stands for total number of patients. The Proteus $s p$ and Enterobactor were rarely found in urine of DM and non-DM patients. CoNS is the most prevalent organism in urine of both DM and non-DM patients.

Table 1. Distribution of Asymptomatic bacteriuria with respect to Age and Sex

\begin{tabular}{|c|c|c|c|c|}
\hline Age (in yrs) & Diabetics with ASB (\%) & Non-diabetics with ASB (\%) & Total with ASB (\%) & Number of patients \\
\hline $16-30$ & $3(25)$ & $2(16.67)$ & $5(41.67)$ & 12 \\
\hline $31-40$ & $3(16.67)$ & $2(11.12)$ & $5(27.78)$ & 18 \\
\hline $41-50$ & $10(20)$ & $5(10)$ & $15(30)$ & 50 \\
\hline$>50$ & $32(26.67)$ & $15(12.5)$ & $\mathrm{P}=0.659, \mathrm{NS}$ & 120 \\
\hline & $\mathrm{P}=0.783, \mathrm{NS}$ & $\mathrm{P}=0.574, \mathrm{NS}$ & $10(14.28)$ & 70 \\
\hline Sex & \multicolumn{5}{|l|}{} & $62(47.69)$ & 130 \\
\hline Male & $6(8.57)$ & $20(15.38)$ & $\mathrm{P}<0.001, \mathrm{~S}$ & \\
\hline Female & $42(32.30)$ & $\mathrm{P}=0.002, \mathrm{~S}$ & $72 / 200(36 \%)$ & 200 \\
\hline
\end{tabular}


Table 2. Frequency of Urine isolates among Diabetics and non-diabetics

\begin{tabular}{|c|c|c|c|c|}
\hline Urine isolates & $\begin{array}{c}\text { Diabetics } \\
\mathrm{N}(\%)\end{array}$ & $\begin{array}{c}\text { Non-diabetics } \\
\mathrm{N}(\%)\end{array}$ & $\begin{array}{c}\text { Total No. of } \\
\text { Isolates }(\%)\end{array}$ & Chi $^{2}$ Test \\
\hline $\begin{array}{c}\text { Coagulase Negative } \\
\text { Staphylococci (CoNS) }\end{array}$ & $22(36.66)$ & $10(35.71)$ & $32(36.36)$ & $\mathrm{P}=0.01, \mathrm{~S}$ \\
\hline E. Coli & $10(16.66)$ & $06(21.42)$ & $16(18.18)$ & $\mathrm{P}>0.05, \mathrm{NS}$ \\
\hline Klebsiella sp & $06(10)$ & $08(28.57)$ & $14(15.9)$ & $\mathrm{P}<0.001, \mathrm{~S}$ \\
\hline Proteus sp & $0(0)$ & $01(3.57)$ & $01(3.57)$ & $\mathrm{P}>0.05, \mathrm{NS}$ \\
\hline Candida sp & $12(20)$ & $01(3.57)$ & $13(14.78)$ & $\mathrm{P}=0.01, \mathrm{~S}$ \\
\hline Streptococcus sp & $03(5)$ & $00(00)$ & $03(3.4)$ & $\mathrm{P}>0.05, \mathrm{NS}$ \\
\hline Staphylococcus aureus & $02(3.33)$ & $01(3.57)$ & $03(3.4)$ & $\mathrm{P}>0.05, \mathrm{NS}$ \\
\hline Enterobactor & $01(1.66)$ & $00(00)$ & $01(1.13)$ & $\mathrm{P}>0.05, \mathrm{NS}$ \\
\hline Serratia & $04(6.66)$ & $01(3.57)$ & $05(5.68)$ & $\mathrm{P}>0.05, \mathrm{NS}$ \\
\hline Total No. of Isolates & 60 & 28 & 88 & \\
\hline
\end{tabular}

Table 3. Antibiotic Resistance of Urinary E. coli and Klebsiella species among Diabetics and Non-diabetics

\begin{tabular}{|c|c|c|c|c|}
\hline \multirow{2}{*}{ Antimicrobial drug } & \multicolumn{2}{|c|}{ Diabetics } & \multicolumn{2}{c|}{ Non-diabetics } \\
\cline { 2 - 5 } & $\begin{array}{c}\text { E.coli } \\
\%\end{array}$ & $\begin{array}{c}\text { Klebsiella sp } \\
\%\end{array}$ & E.coli $\%$ & Klebsiella sp \% \\
\hline Penicillin & 11.53 & 3.33 & 12.5 & 4.87 \\
\hline Nalidixic acid & 19.23 & 15 & 12.5 & 9.75 \\
\hline Augmentin & 7.69 & 1.66 & 8.33 & 2.43 \\
\hline Ceftriaxone & 7.69 & 13.33 & 8.33 & 19.51 \\
\hline Cefuroxime & 0.0 & 16.66 & 0.0 & 4.87 \\
\hline Ciprofloxacin & 0.0 & 6.66 & 0.0 & 12.19 \\
\hline Levofloxacin & 0.0 & 1.66 & 0.0 & 0.0 \\
\hline Gentamicin & 15.38 & 21.66 & 20.83 & 24.39 \\
\hline Co-trimoxazole & 23.07 & 5 & 29.16 & 4.87 \\
\hline Azithromycin & 7.69 & 1.66 & 4.16 & 7.31 \\
\hline Doxycycline & 7.69 & 13.33 & 4.16 & 9.75 \\
\hline
\end{tabular}

\section{Levofloxacin is the most effective antibiotic against $E$. coli and Klebsiella sp.}

We tested efficacy of different antibiotics (Penicillin, Nalidixic acid, Augmentin, Ceftriaxone, Cefuroxime, Ciprofloxacin, Levofloxacin, Gentamicin, Co-trimoxazole, Azithromycin Doxycycline) against bacterial species by testing using E. coli and Klebsiella sp isolated from urine of $\mathrm{DM}$ and non-DM patients. The prevalence of $E$. coli has no significant difference in DM and non DM patients $(\mathrm{p}=0.24)$; while Klebsiella $s p$ was found to be more frequently associated with diabetic patients (Table 2). We observed that Klebsiella $s p$ isolated from DM patients were resistant against Cefuroxime and Ciprofloxacin; while both these antibiotics were effective in inhibiting growth of $E$. coli isolated either from DM and non-DM patients (Table 3). Antibiotics such as Gentamicin and Co-trimoxazole did not effectively inhibit growth of $E$. coli isolated both from DM and non-DM patients (Table 3). All together, our current study show Levofloxacin is potent antibiotic against E.coli and Klebsiella sp in Patna district

Levofloxacin is potent antibiotic against E.coli and
Klebsiella sp; while other antibiotic such as penicillin, Nalidixic, Gentamicin, Co-trimoxazole are show resistance against E.coli and Klebsiella sp.

\section{Discussion}

Asymptomatic bacteriuria is a major concern for diabetes mellitus patients. No significant information was available on the occurrence of ASB amongst diabetics versus non diabetics, and effect of factors like age and gender on the occurrence of ASB in Patna district. Therefore, the present study was aimed to determine the prevalence and spectrum of microorganisms responsible for asymptomatic bacteriuria in DM verus non-DM. The study also aimed to determine antimicrobial resistance of urinary isolates in DM and non-DM subjects.

The present study revealed an overall prevalence of ASB in DM compared to non-DM subjects. Our result are in consensus with that of the earlier reports which reported prevalence of ASB in diabetics (36.2\%) compared to non-diabetics (18.5\%) [5]. In Cameroon, high prevalence 
$(35.2-58.3 \%)$ of bacteriuria has been reported $[14,17]$. On the contrary, the prevalence of ASB in this study is higher than that of some studies which recorded $5.3-26 \%$ in diabetics and $3.5-15 \%$ in non-diabetics $[3,4,18,19$, 20].Consequently, the issue of prevalence of ASB remains debatable. This inconsistency has been attributed due to variations in sample size, geographical location, culture or screening method [11]. Our studies also show ASB was significantly higher in DM and non-DM patient. This is in line with majority of previous reports [7, 12].

As per our study, the prevalent microorganisms found in ASB in Patna region were coagulase negative Staphylococcus (36.36\%), Klebsiella sp. (15.9\%), Candida sp. (14.78\%), E. coli. (18.18\%) and Serratia sp. (5.68\%) each. As per our study the most prevalent microorganisms found in ASB was coagulase negative Staphylococcus $(36.36 \%)$, whereas most of the studies in other regions report E. coli to be the most predominant [5-9]. The predominance of bacteria other than $E$. coli in the urinary tract has been reported by some of the studies. Recent studies in Nigeria show that Staphylococcus aureus was the most common bacteria in urine of DM and non-DM patient [12]. The Staphylococcus sp. is found as a normal skin flora. The high prevalence of Staphylococcus sp of ASB may be due inclosed inside of urinary tract during sexual intercourse [12]. The high prevalence of CoNS might be due to inappropriate use of antibiotics which may encourage the proliferation of highly resistant bacteria such as CoNS [21]. The frequency of isolation of uropathogens was similar among DM and non-DM except for Candida $s p$. and Serratia $s p$. that were more frequent in DM patients. On the contrary, Klebsiella $s p$ was isolated more from non-DM. The precise reason why there is difference in ASB of diabetics and non-diabetics is not well understood. One of the simple reason proposed that excess glucose promotes the growth of some bacterial species such as Candida sp. [22].

Results of the antibiotic susceptibility test of DM and non-DM patients show that there was significant difference in the resistant pattern of Cefuroxime and Ciprofloxacin. The rate and spectrum of antibiotic resistance in this study is similar to that of studies conducted in other developing countries [3, 4]. High resistance to Co-trimoxazole and Nalidixic acid may be due its frequent use in Patna district to treat urinary tract infections and other infectious diseases. In the present study, we found $E$. coli strains demonstrated multi-drug resistance especially to Gentamicin, Nalidixic acid, Doxycycline, Cefuroxime and erythromycin. Multi-drug resistance of $E$. coli is a common phenomenon as reported by other authors $[5,10,18]$. The most resistant Gram positive organisms were CoNS. These bacteria have been reported to show high resistance to multiple antibiotics [21]. The $15 \%$ resistance of CoNS to Gentamicin and a corresponding $22.5 \%$ resistance to Vancomycin observed in this study could be an indication of the circulation of Gentamicin-Vancomycin resistant strains in the community. Infections with these strains are very difficult to treat and the consequences could be fatal.

\section{Conclusions}

The major findings of this study were Asymptomatic Bacteriuria is more prominent in DM female patients. Coagulase negative staphylococcus is most prevalent organism in urine sample in Patna region. Levofloxacin was found to be the most effective antibiotic against $E$. coli and Klebsiella sp. of ASB, in Patna region. In general, there is no significant difference in the resistance pattern between DM and non-DM patients. These studies strengthen earlier observation that shows the antibiotic resistance distribution of ASB in Patna region, India.

\section{REFERENCES}

[1] Geerlings SE, Stolk RP, Camps MJL, Netten PM, Collet TJ, Heopelman AIM, Risk factors for symptomatic urinary tract infection in women with diabetes. Diabetes Care 2000a; 23: 1737-174.

[2] Joshi N, Caputo GM, Weitekamp MR, Karchmer AW. Infections in patients with diabeties mellitus. N Engl J Med 1999; 341: 1906-1912.

[3] Alebiosu CO, Osinupebi OA, Olajubu FA. Significant asymptomatic bacteriuria among Nigerian type 2 diabetics. J natl Med Assoc 2003; 95: 344-351.

[4] Lyamuya EF, Moyo Sj, Komba EV, Haule M. Prevalence, antimicrobial resistance and associated risk factors for bacteriuria in diabetic women in Dar es Salaam, Tanzania. Afr J Microbiol Res 2011; 5 (6): 683-689.

[5] Bonadio M, Costrarelli S, Morelli G, Tartaglia T. The influence of diabetes mellitus on the spectrum of uropathogens and the antimicrobial resistance in elderly adult patients with urinary tract infection. BMC Infections Diseases 2006; 6 (54): $1-7$.

[6] Manhal FS, Gauad SA. Asymptomatic bacteriuria in pregnant and diabetic women. Al Kindly Col Med J 2011; 7 (1): 39-46.

[7] Zamanzad B, Moiezzi M. Prevalence of asymptomatic bacteriuria and associated host factors in women with diabetes type 2. J Res health Sci 2006; 6 (1): 14-20.

[8] Ishay A, Lavi I, Luboshitzky R. Prevalence and risk factors for asymptomatic bacteriura in women with Type 2 diabets mellitus. Diabet Med 2006; 23: 185-188.

[9] Geerrlings SE, Stolk RP, M. Camps MJL, Netten PM, Hoekstra JB, Bouter PK, et al. Asymptomatic bacteriuria may be considered a complication in women with diabetes. Diabetes Care 2000b; 23: 744-749.

[10] Ophori EA, Imade P, Johnny EJ. Asymptomatic bacteriuria in patients with diabetes. J Bacteriol Research 2010; 2 (2): 14-17.

[11] Assel Mt, Al-Meer FM, Al-Kuwari MG, Ismail MF Prevalence and preditor of asymptomatic bacteriuria among pregnant women attending Primary health care in Qatar Middle East J Fam Med 2009; 4:14-17.

[12] Omoregie R, Erebor JO, Ahonkhai I, Isibor JO, Ogofere H. 
Observed changes in the prevalence of uropathogens in Benin City,Nigeria. Nz J Med Lab Science 2008; 29-31

[13] Mbanya JC, Ngogang J, Salah JN, E. Minkoulou E, Balkau B. Prevalence of NIDDM and impaired glucose tolerance in a rural and urban population in Cameroon.Diabetologia 1997; 40: 824-829.

[14] Akoachere JFT, Suylika Y, Njom HA, Esemu NS. Etiologic profile and antimicrobial susceptibility of community-acquired urinary tract infection in two Cameroonian towns. BMC Research notes 2012; 5: 219

[15] Gangoue PJ, Koulla SS, Ngassam P, Adiogo D, Ndumbe P. Antimicrobial activity against Gram negative bacilli from Yaounde Central Hospital, Cameroon. African Health Sciences 2006; 6 (4): 232-235.

[16] Clinical and Laboratory Standards, Wayne PA.Performance standards for antimicrobial disk susceptibility tests. Approved standard. Clinical and Laboratory Standards Institute 2006; ninth edition Document M2-A9.

[17] Yuyun MF, Angwafo III FF, Koulla-Shiro S,Zoung-Kanyi J.
Urinary tract infections and genitourinary abnormalities in Cameroonian men. Trop Med Int Health 2004; 9 (4): 520525.

[18] Hamdan HZ, Ziad AHM, Ali SK, and Adam I. Epidemiology of urinary tract infections and antibiotics sensitivity among pregnant women at Khartoum North Hospital. Annals Clin Microbiol Antimicrob 2011; 10(2).

[19] Odetoyin WB, Aboderin AO, Ikem RT,Kolawole BA, Oyelese AO. Asymptomatic bacteriuria in patients with diabetes mellitus in Ile-Ife, South-West, Nigeria. East Afr MedJ2008; 85:18-23.

[20] Wogu MD, Ogbebor NE. Prevalence of asymptomatic bacteriuria in secondary school students in Benin City. Afr Res Rev 2011; 5 (4):145-151.

[21] Kloos WE, Bannerman TL. Update on the clinical significance of coagulase-negative Staphylococci. Clin Microbiol Rev 1994; 7 (1): 117-140.

[22] Al-Attas SA, Amro SO. Candidal colonization, strain diversity and antifungal Susceptibility among adult diabetic patients. Annals of Saudi Medicine 2010; 30 (2): 101-108. 